\title{
Correction to: Comparing Percutaneous Transluminal Angioplasty and Stent Placement for Treatment of Subclavian Arterial Occlusive Disease: A Systematic Review and Meta-Analysis
}

\author{
Ahmed T. Ahmed ${ }^{1,2} \cdot$ Khaled Mohammed $^{1,2} \cdot$ Monzer Chehab $^{3} \cdot$ Waleed Brinjikji $^{4}$.

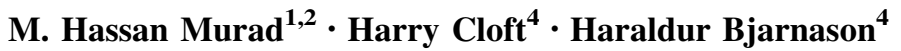

Published online: 26 January 2018

(C) Springer Science+Business Media, LLC, part of Springer Nature and the Cardiovascular and Interventional Radiological Society of Europe (CIRSE) 2018

\section{Correction to:}

Cardiovasc Intervent Radiol (2016) 39:652-667 https://doi.org/10.1007/s00270-015-1250-9

The original version of this paper contained an error.

The name of M. Hassan Murad, though correctly appearing in the published version, was incorrectly displayed in indexing sites. This error occurred because of the incorrect tagging of the author's name in the metadata of this article.

The purpose of this Erratum is the correction of metadata.

Therefore, indexing sites should now reflect the author's name as Murad, M. H.
The original article can be found online at https://doi.org/10.1007/ s00270-015-1250-9.

Ahmed T. Ahmed

Ahmed.Ahmed1@mayo.edu

Khaled Mohammed

Mohammed.Khaled@mayo.edu

Monzer Chehab

moe.chehab@beumont.edu

Waleed Brinjikji

Brinjikji.Waleed@mayo.edu

M. Hassan Murad

Murad.Mohammad@mayo.edu

Harry Cloft

Cloft.Harry@mayo.edu

Haraldur Bjarnason

Bjarnason.Haraldur@mayo.edu
1 Evidence-Based Practice Research Program, Mayo Clinic, 2001 st Street Southwest, Harwick Building 2-50, Rochester, MN 55905, USA

2 Division of Preventive, Occupational and Aerospace Medicine, Mayo Clinic, 200 1st Street Southwest, Rochester, MN 55905, USA

3 Department of Diagnostic Radiology and Molecular Imaging, Oakland University William Beaumont School of Medicine, 3601 W 13 Mile Road, Royal Oak, MI 48073, USA

4 Department of Radiology, Mayo Clinic, 200 1st Street Southwest, Rochester, MN 55905, USA 